\title{
Renal Transplantation in Patients With Lower Urinary Tract Dysfunction
}

\author{
B. Parada, A. Figueiredo, A. Mota, and A. Furtado
}

$\mathrm{P}$ ATIENTS WITH lower urinary tract anomalies have previously been considered poor candidates for renal transplantation. However, newer techniques of diagnosis and reconstructive surgery have extended the indications and improved the success rate of renal transplantation in these patients. ${ }^{1,2}$

\section{PATIENTS AND METHODS}

Between June 1980 and December 2001, 1076 kidney transplantations were performed in our department, including 29 transplantations on 27 patients with lower urinary tract pathology (Table 1). The average age of the recipients was 29 years (range 13 to 51) and the male:female patient ratio was 23:4. The etiology of the abnormal lower urinary tract was neurogenic bladder in 10 patients (meningomyelocele in 6, spine trauma in 3 , and diabetes in 1), posterior urethral valves in 9, bladder neck obstruction in 3 , previous cystectomy in 4 (severe pelvic trauma in 2 cases, acute hemorrhagic cystitis and tuberculosis in 1), and bladder contraction after tuberculos in 1. Pretransplantation evaluation included a medical interview, physical examination, urinalysis, urine culture, renal ultrasound, cystourethrography, and urodynamic studies. Augmentation cystoplasty had been previously performed in 4 $(14.8 \%)$ cases; $5(18.5 \%)$ patients had urinary drainage into an ileal conduit, and $6(22.2 \%)$ patients, a cutaneous ureterostomy. The remaining $12(44.5 \%)$ patients underwent transplantation into a native bladder. Three patients $(10.3 \%)$ received kidneys from living related donors. The graft was inserted in the right iliac fossa using an extraperitoneal approach in all cases.

\section{RESULTS}

At a mean follow-up of 44 months, the actuarial patient and graft survival rates are $92.6 \%$ and $77.8 \%$, respectively. Two patients died, one due to septicemia and another due to peritonitis after perforation of the augmented bladder. Six grafts were lost due to chronic dysfunction in 3 cases, renal artery thrombosis in 2, and noncompliance with immunosuppression in 1 . In patients with a functioning graft, the mean serum creatinine level is $1.4 \mathrm{mg} / \mathrm{dL}$ (range, 0.9 to 2.6 ). Acute rejection, which developed in 8 patients, was reversed with antirejection therapy.

Surgical complications occurred in six $(20.7 \%)$ cases: one perforation, two arterial thromboses, one lymphocele, one wound infection, and one obstruction of the ureter that was corrected by open surgery.

Among the 12 patients who had their native bladder

\begin{tabular}{clc}
$\begin{array}{c}\text { Table 1. Patients With Lower Urinary Tract Anomalies and } \\
\text { Urological Procedures }\end{array}$ \\
\hline Etiology & \multicolumn{1}{c}{$\begin{array}{c}\text { Urological } \\
\text { Procedure/Urinary } \\
\text { Drainage }\end{array}$} & No. \\
\hline Neurogenic bladder & Bladder augmentation & 3 \\
& Urinary diversion & 2 \\
& CIC & 4 \\
Posterior urethral valves & Indwelling catheter & 1 \\
& Bladder augmentation & 1 \\
Bladder neck obstruction & Urinary diversion & 3 \\
& CIC & 5 \\
Cystectomy & Urinary diversion & 1 \\
Tuberculosis & Indwelling catheter & 2 \\
& Urinary diversion & 4 \\
& Urinary diversion & 1
\end{tabular}

Abbreviation: CIC, clean intermittent self-catheterization.

preserved, 9 perform intermittent self-catheterization (Table 1). Three patients with meningomyelocele also require anticholinergic agents. Two of three patients with bladder neck obstruction and a paraplegic patient have a permanent indwelling catheter.

Urinary tract infection was the most common posttransplantation complication, being documented in 21 (77.8\%) patients.

\section{DISCUSSION}

Patients with congenital or acquired lower urinary tract disease often present complex urological management problems before transplantation. ${ }^{2}$ Advances in surgical technique, immunosuppression, and increasing experience have extended the availability and success rate of renal transplantation in patients who were previously considered unsuitable. ${ }^{3,4}$ Despite the increasing success of renal transplantation, as measured by patient and graft survivals. ${ }^{5}$ urological disease may adversely influence outcome of this procedure due to urinary tract infection, surgical complications, allograft dysfunction, and graft loss. ${ }^{6}$ Pretransplanta-

From the Department of Urology and Transplantation, University Hospital of Coimbra, Coimbra, Portugal.

Address reprint requests to $\mathrm{B}$. Parada, Department of Urology and Transplantation, Coimbra University Hospital, 3049 Coimbra Codex, Portugal. E-mail: parada.belmiro@netc.pt 
tion assessment of lower urinary tract function is important. ${ }^{1}$ The goal of therapy is to provide a sterile, compliant, nonrefluxing, low pressure reservoir that is continent and easily emptied. ${ }^{3}$ This regimen may involve anticholinergic pharmacological agents as well as clean intermittent selfcatheterization to maintain low bladder pressure and regular emptying. Because of a low capacity, noncompliant reservoir, bladder augmentation was performed in four patients, using ileum with good results. Eleven patients had urinary diversion due to hypertonic, functionally abnormal bladders or after cystectomy. As in most series, we performed bladder augmentation or an ileal conduit before the renal transplantation to decrease the risk of posttransplantation complications. ${ }^{2,3,5,7,8}$ The most common cause of graft loss among our patients was immunologic. Although urinary tract infections were frequent, they did not seem to affect the long-term function of the graft. ${ }^{5,8}$ No urinary stones or chronic metabolic acidosis were observed in our patients.

\section{REFERENCES}

1. Toda $\mathrm{F}$, Tanabe $\mathrm{K}$, Ishiwaka $\mathrm{N}$, et al: Transplant Proc 30:3007, 1998

2. Marshall FF, Smolev JS, Spees EK, et al: J Urol 127:1078, 1982

3. Koo HP, Bunchman TE, Flynn JT, et al: J Urol 161:240, 1999

4. Warady BA, Hébert D, Sullivan EK, et al: Pediatr Nephrol $11: 49,1997$

5. Hatch DA, Koyle MA, Baskin LS, et al: J Urol 165:2265, 2001

6. Sheldon CA, Gonzalez R, Burns MW, et al: J Urol 152:972, 1994

7. Coosemans W, Baert L, Kuypers D, et al: Transplant Proc 33:2493, 2001

8. Martin MG, Castro SN, Castelo LA, et al: J Urol 165:393, 2001 